\title{
INFLUENCE OF PERIODIC PAUSES ON FATIGUE LIFE OF AN AUTOMOBILE HORN BRACKET UNDER VARIABLE AMPLITUDE LOADING
}

\author{
Clayton Mamedes Angelo \\ Wilson de Simone Carlos \\ Cláudio Geraldo Schön ${ }^{2}$
}

\begin{abstract}
A metallic horn bracket used in a typical passenger's car has been tested mounted in the vehicle by using two different approaches: in a proving ground (in the field) and using a road simulator (in a laboratory). The results lead to different durabilities (respectively, failure at $18 \%$ and II\% of the complete test). This difference is attributed to the presence of pauses in the field test, which are not present in the road simulator test spectrum. This hypothesis was tested by introducing artificial periodic pauses in bench tests. It is shown that the average fatigue life of the component, which is 170922 cycles in the continuous test, is increased to 239434 cycles by introducing 5 hour pauses each 100000 cycles, to 240848 cycles by using 10 hour pauses, and to 1043743 cycles by using 45 hour pauses. The results are discussed with regard to fatigue testing and durability design.
\end{abstract}

Keywords: Spectrum loads; Structural integrity; Fatigue life; Automotive components; Alloy steel.

\section{INFLUÊNCIA DE PAUSAS PERIÓDICAS SOBRE A VIDA EM FADIGA DE UM SUPORTE DE BUZINA AUTOMOTIVO SOB CARREGAMENTO DE AMPLITUDE VARIÁVEL}

\section{Resumo}

Um suporte de buzina metálico empregado em um carro de passageiros típico foi testado como montado na estrutura do veículo usando dois procedimentos: em uma pista de testes (no campo) e em um simulador de estradas (no laboratório). Os resultados mostram diferentes durabilidades (respectivamente falha em $18 \%$ e $11 \%$ do teste completo). Essa diferença foi atribuída à existência de pausas no teste de campo, que não são presentes no espectro do ensaio usando o simulador de estradas. A hipótese foi testada introduzindo-se pausas artificiais periódicas em testes de bancada. Observa-se que a vida média em fadiga do componente, que é de 170922 ciclos no teste contínuo, aumenta para 239343 ciclos com pausas de 5 horas a cada 100000 ciclos, para 240848 pelo uso de pausas de 10 horas e para 1043743 ciclos usando-se pausas de 45 horas. Os resultados são discutidos em função da relação entre ensaios de fadiga e a confiabilidade estrutural de componentes.

Palavras-chave: Carregamento em espectro; Integridade estrutural; Vida em fadiga; Componente automotivo; Aço ligado.

\section{INTRODUCTION}

It is very important to the industry to deliver competitive products that can properly perform their functions to the final customer during their required useful life. One existing tool for achieve these objectives is the usage of work durability and fatigue tests. The required parameters for these tests must be reliable when compared to the loads acting on the component during its real performance in a procedure known by the German term Betriebsfestigkeit [I-3]. In order to achieve these results, the fatigue tests under variable amplitude (VA) loading came into existence. This is necessary due to the essentially non-linear and non-local character of fatigue damage,

'Volkswagen do Brasil SA, São Bernardo do Campo, SP, Brasil. E-mail: clayton.angelo@volkswagen.com.br

${ }^{2}$ Departamento de Engenharia Metalúrgica e de Materiais, Escola Politécnica, Universidade de São Paulo - USP, São Paulo, SP, Brasil. 
which leads to load interaction effects [4-6]. Perhaps the most strange demonstration of this complex behavior is in the so called "overload" phenomenon, in which a single cycle with a sudden peak load in an otherwise constant amplitude (CA) loading leads to a measurable delay in crack propagation [7-I0]. It's counterpart phenomenon, on the other hand, called "underload" (a cycle with a load reduction inserted in the middle of a otherwise CA loading leads to a measurable crack growth acceleration), shows that the task of predicting crack growth in components subject to VA loading is considerable difficult. A great deal of effort has been dedicated to understand and deal with this complexity [I I-16]. The leading approach, starting with the seminal work of Wolf Elber [17], is "crack closure" in which the non-linear (and especially, the non-local) character of fatigue crack growth is attributed to events left behind, in the wake, of a crack, by the plastic zone at crack tip at the moment of perturbation. Modeling using the "crack closure" approach is able to reproduce experimental crack growth data under complex loading schedules (see, for example, ref. [18]). Alternate views, however, exist, and attribute the complexity to residual stresses developed in the plastic zone, ahead of the crack tip [19]. In spite of indications of a mechanistic justification for these phenomena, at least in copper [20], fatigue crack propagation under VA loading keeps being prone to present "strange" behaviors.

The main objective of this work is to report one of such "strange" behaviors. It is based on the working experience of one of the present authors (CMA), who observed discrepant results on fatigue testing of an automotive component in a test track (using instrumented passenger vehicles) compared with accelerated bench tests using the load spectrum acquired in the same test track. This discrepancy is most surprising in the sense that fatigue life in the test track is larger than the ones obtained in the bench tests. There are several possible reasons for obtaining different fatigue lives in bench tests and in test tracks. Load spectra are acquired in discrete points in the components, then they are filtered, have their frequency enhanced and then are applied to test components by actuators in a testing machine $[2,21,22]$. The loading devices can reach presently quite sophisticated setups [23], however, actual loading of a component, mounted in a structure will always be different. There is, however, at least one drastic difference between testing in a track and in a machine: in a test track the test must be paused periodically for the driver's comfort or due to mechanical issues, like maintenance. It is the working hypothesis of the present work that these pauses are responsible for the discrepancy. This will be tested by comparing results obtained in a test track with those obtained in a road simulator using the same spectrum (but without pausing the test), and then by applying artificial pauses in VA bench tests, monitoring the variations in the fatigue durability of the component.

\section{METHODOLOGY}

The target of this work is a metallic horn bracket, which is used in light passenger's vehicles. Although this is a simple component, it is subject to conflicting design specifications. From one side, the component has to fulfill structural requirements, being responsible for the fixation of the horn in the vehicle's body. The component, however, is also responsible to define the position of the horn, and therefore, to define its acoustic characteristics, which are subject to regulatory standards (e. g. ABNT NBR 5483 [24]). These acoustic properties are strongly influenced by the bracket geometry. This component is also subjected to a wide range of loadings.

Two similar light vehicles were equipped with instrumented horn brackets (unidirectional LYI certified extensometers from Hottinger Baldwin Messtechnik $\mathrm{GmbH}$, Darmstadt [25]) and submitted to the following fatigue tests:

- Vehicle A - instrumented and tested in a controlled test track (proving ground);

- Vehicle B - tested in a road simulator, with input loads correlated (concerning linear damage accumulation) with the previously described test track.

The investigated component (horn bracket) is made of DCOI - Q/BQB403-2003 carbon steel, with a thickness of $2.53 \mathrm{~mm}$. Their main specified mechanical properties are yield strength between 270 and $410 \mathrm{MPa}$, which is a considerably broad range. The component's schematic drawing is found in Figure I.

The component is formed by a stamped sheet of irregular shape, with a welded nut at one of its ends. The side with the welded nut supports the horn, which is free in the structure, while the other side is attached to the vehicle body. Therefore the component acts as a cantilever beam and, correspondingly, the main efforts correspond, probably, to flexure loads, with a stress concentrations close to the vehicle's attachment end and to the horn attachment point.

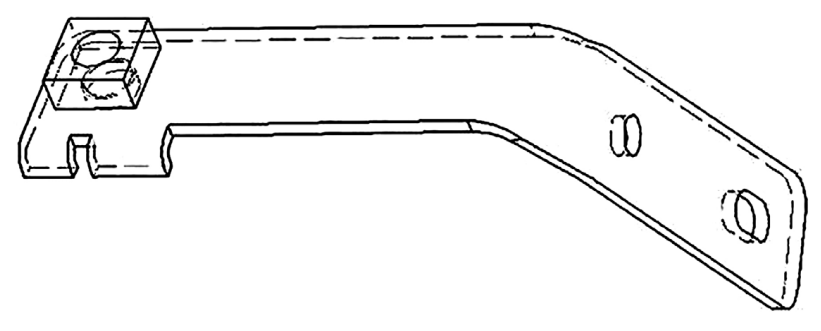

Figure I. The investigated horn bracket. 


\section{I Testing Conditions}

\section{I.I Proving ground test}

The test track is made of several types of asphalt and surface obstacles like bumpers and holes, in order to simulate the critical road conditions in which the vehicle can be driven. These surface obstacles are responsible for the load inputs at the vehicle tires and suspension. Holes provide the major vertical loads, while curves are in charge for the main horizontal loads. There are also several kinds of soil, like asphalt with various surface roughness levels, bricks, mud, water pools and special pavements for vibrational excitation. Through variation on the vehicle load conditions (i.e.: quantity of passengers and/or load at the trunk or roof) and total test mileage it is possible to cover a wide range of damage accumulation in the structure. Using these tools it is possible to achieve extreme damage accumulation, like the ones observed for trucks or off-road vehicles, or to apply loads concerning a light user, like a compact urban vehicle. The driving on the specified test track is made with controlled speeds and procedures, like specified braking points and driving over certain kind of obstacle in accordance with the required damage set up. The drivers are also highly trained in order to correctly follow the special test procedures. This behavior enhances the data reliability.

The load inputs that are generated during the vehicle's driving were collected by a device called Measurement Wheels, from Kistler, which correspond to instrumented wheels which are mounted in the vehicle. Four Measurement Wheels type RoaDyn ${ }^{\circledR}$ S625, Type 9266A, diameter 15" connected with a RoaDyn P Ixy telemetry module, were used.

\subsubsection{Road simulator test}

The road simulator consists of several hydraulic actuators and platforms which simulate road condition over a complete vehicle structure. The load inputs for the road simulator were acquired in the test track through the mentioned data acquisition devices and signal editing tools. In other words, the load spectrum that is applied to the simulator is equivalent to the loads that are generated during the real driving. The largest difference is due to the editing: the removal of parts of the real spectrum that are not representative for damage accumulation (i.e. sections with very low stress amplitude, rests, soft curves) are removed from the final spectrum. This edited spectrum has two main properties:

I. it is shorter than the real one, and

2. it produces the same damage accumulation level.

The main advantage of this system is the possibility to perform a complete test faster than the similar one performed in the test track, in addition no interference of human or environmental sources (e.g. moist weather) are observed in the road simulator. The used simulator is based on the MTS329 Model from MTS.

During the test, the load levels were also monitored using the Kistler Measurement Wheels.

\subsubsection{Bench tests}

In order to test the horn bracket in an isolated way, a bench test was constructed using one Spectra ${ }^{\circledR}$ ST7000 control unit, one $50 \mathrm{kN} \mathrm{HBM}^{\circledR}$ load cell and one um $60 \mathrm{kN}$ Schenk ${ }^{\circledR}$ actuator, Model PVQ. The samples were attached to the machine using a simple device and a connecting rod.

A fatigue spectrum obtained based on the loads acting only over the bracket on vehicles $A$ and $B$ was constructed and uploaded to the bench test for the fatigue tests with horn bracket samples. For these bench tests the following text schedules were simulated:

- Baseline - a continuous test up to sample rupture, without pause in the load application;

- $5 \mathrm{~T}$ - tests until rupture, with a 5 hours pause(s) between the load applications;

- IOT - tests until rupture, with a 10 hour pause(s) between load applications;

- $45 \mathrm{~T}$ - tests until rupture, with a 45 hours pause(s) between load applications.

These pauses were periodically introduced after 100.000 cycles of the load spectrum application. The time interval between the applications of the pauses was, in average, 3 hours. Up to nine samples were tested for each condition. The case of the 45T tests is the most critical, since only three samples were tested (due to test time limitations).

\section{RESULTS AND DISCUSSION}

\section{I Complete Vehicle Tests}

In the comparison between vehicles A (proving ground) and B (road simulator) is was observed that, for a fixed test duration (equivalent number of cycles, and hence, accumulated damage), the components failed respectively at $18 \%$ and $11 \%$ total elapsed test. These results are, evidently, obtained with a single sample, so the difference could be simply justified by the stochastic nature of fatigue failure. Observation of the broken components (Figure 2), however, shows that failure occurred at the same site (the region close to the weld between the nut and the steel sheet). Observation of the fracture surfaces also show that no large differences in the failure mechanism are identified. The mechanical properties of the components were measured according to standard DIN EN I0002-I [26], machining a testpiece post mortem. Measured tensile strengths for the component belonging to vehicle $\mathrm{A}$ was $333 \mathrm{MPa}$ and for 

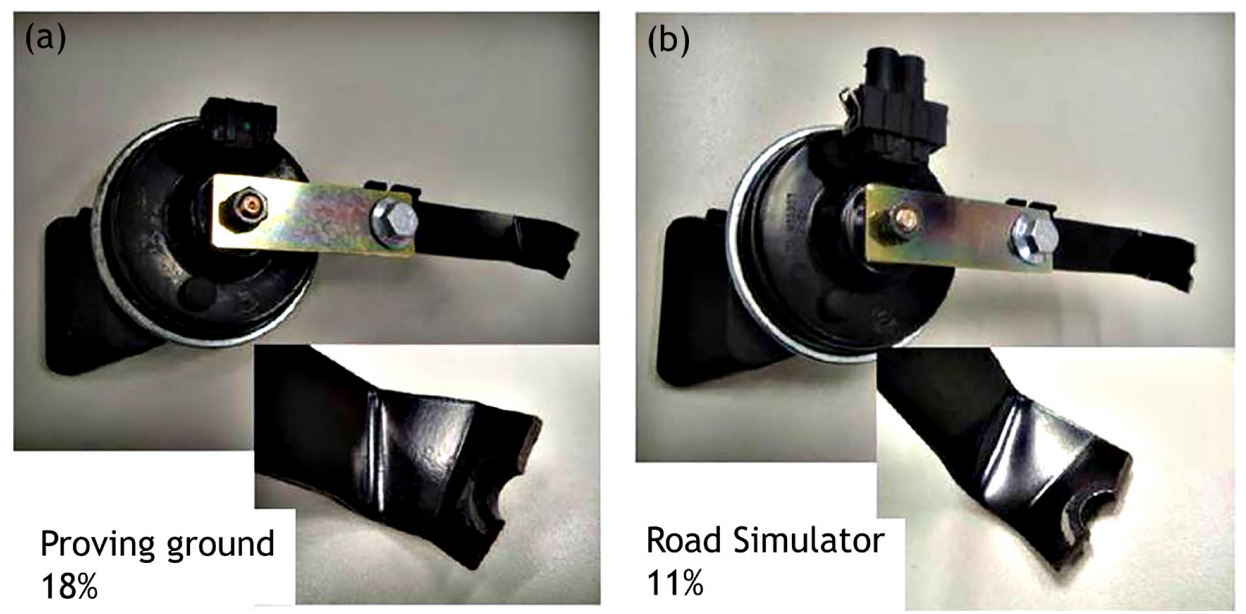

Figure 2. The failed components: Vehicle (A) Proving ground, and Vehicle (B) Road simulator.

(a)

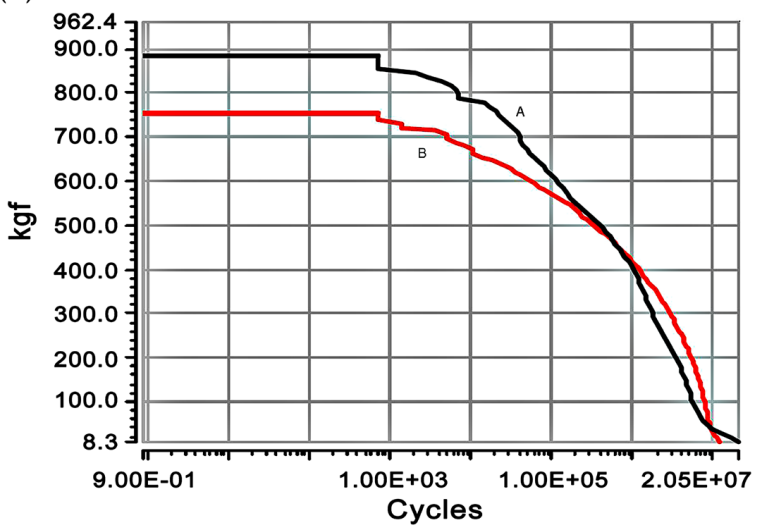

(b)

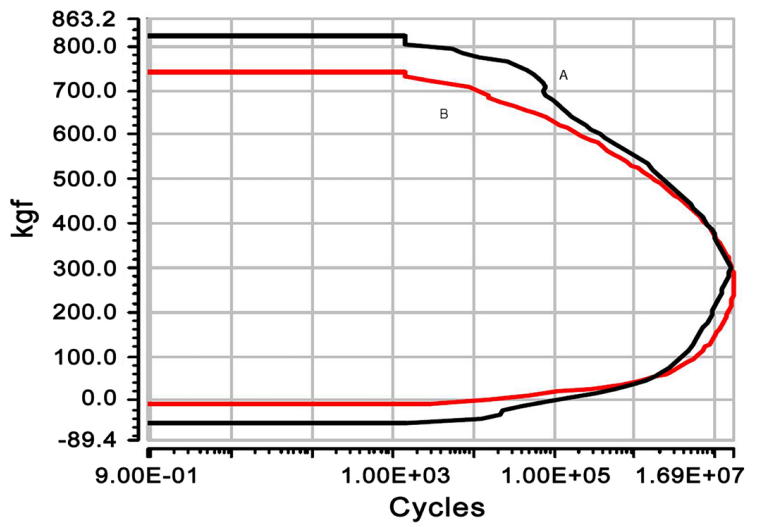

Figure 3. Histograms corresponding to the spectra acquired using the measuring wheels for the vehicle tested in the proving ground $(\mathrm{A})$ and in the road simulator (B) using two counting techniques: levels-crossing (a) and range-pair (b).

vehicle B $295 \mathrm{MPa}$, both values comply with the specified ranges for the steel. The observation, thus, suggests that material and failure modes are equivalent and, thus, failure in conditions of the proving ground test occurs at a significantly larger accumulated damage level compared with the road simulator test.

Another possible reason for the observed difference could be justified by significant changes in the applied load spectrum. Figure 3 shows the histograms obtained using the measurement wheels with two cycle count methods (Level Crossings, LC, and Range Pair, RP [27]). The spectra obtained for both the proving ground and the road simulator are equivalent, with minor differences in the high amplitude cycles. The Power Spectral Density (PSD) analysis [28] was performed in both signals and the result is shown in Figure 4, again, the spectra are similar also in this aspect, showing broad maxima around 20,85 and $175 \mathrm{~Hz}$, with most of the highly intense cycles concentrated at the lowest frequencies.

Similarly, the spectra measured at the component were analyzed and the resulting histograms are shown in Figure 5. Comparing with the measuring wheel spectra,

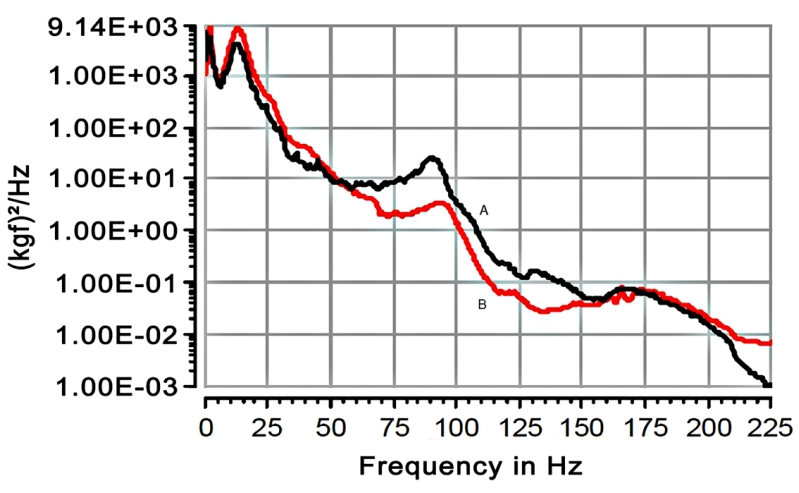

Figure 4. PSD analysis of the signals shown in Figure 3 for the vehicles tested in the proving ground $(A)$ and in the road simulator $(B)$.

the differences between the proving ground and the road simulator cases are further reduced, such that the working spectra observed at the component may be assumed to be indistinguishable. Therefore, they cannot justify the observed difference in fatigue lives. 
(a)

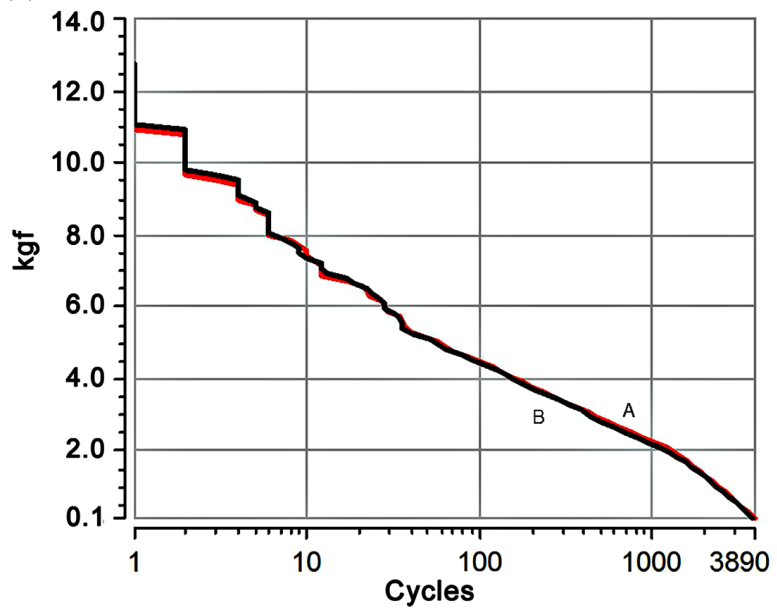

(b)

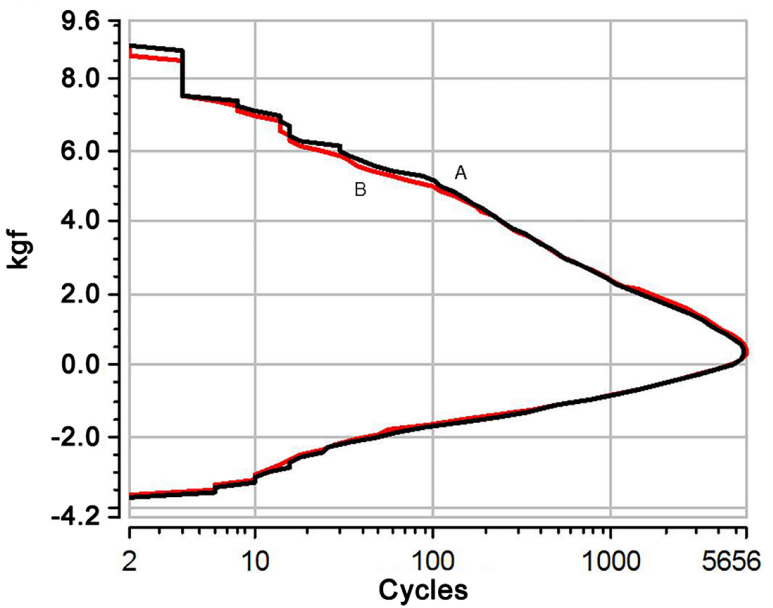

Figure 5. Histograms corresponding to the spectra acquired at the investigated component for the vehicle tested in the proving ground (A) and in the road simulator (B) using two counting techniques: levels-crossing (a) and range-pair (b).

\subsection{Bench Tests}

Based on the observations described in the previous section it is possible to conclude that the proving ground results lead to a higher component fatigue durability, compared with the results obtained in the road simulator, even considering that the load spectrum is identical in both cases. As explained in section I, the largest difference between the road simulator test and the proving ground one is the fact that the later is periodically paused. There are, however, random variables acting in the proving ground which could also justify this difference (the most important being the weather). The bench tests allow to investigate the effect of periodic pauses in the component durability, isolating these random variables, by performing the test in the controlled environment of a laboratory, including pauses.

Figure 6 shows the results of the individual tests in all samples and Table I show the calculated average and standard deviation for the set. It is observed that the introduction of periodic pauses with 5 or 10 hour duration each 100000 cycles leads to a significant increase in the component's fatigue life compared with the test performed without pause. Comparing the results for the tests with 5 and $10 \mathrm{~h}$ pauses allows no conclusion. The results obtained using $10 \mathrm{~h}$ pauses gives a somewhat larger fatigue life compared with the case of $5 \mathrm{~h}$ pauses, but the difference is, evidently not statistically significant. The results obtained using $45 \mathrm{~h}$ pauses, however, clearly show consistently larger fatigue lives of the components. The results of the bench tests, therefore support the validity of the working hypothesis: pauses in the proving ground test may affect the durability of a component, increasing its fatigue life.

The origin of this effect is puzzling. Breaking a vehicle (in the proving ground) or stopping a fatigue test (in the bench test with pauses) surely results in transient inertial loads (for instance, while breaking to or accelerating from rest) which are not present in a continuous tests (either

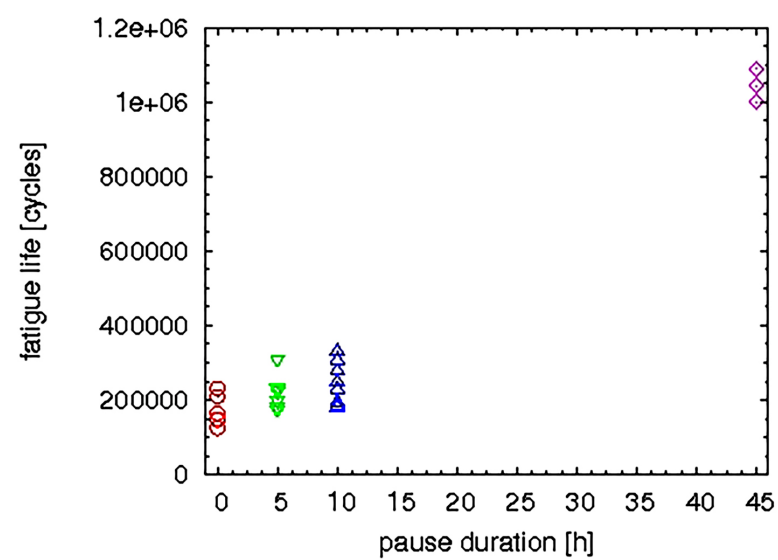

Figure 6. Results of the individual bench tests. Each point correspond to the result of a single test.

Table I. Results of the bench tests, average fatigue lives and standard deviation of the population

\begin{tabular}{cccc}
\hline Condition & $\begin{array}{c}\text { Number } \\
\text { samples }\end{array}$ & $\begin{array}{c}\text { Life } \\
\text { [cycles] }\end{array}$ & $\begin{array}{c}\text { Std. Dev. } \\
\text { [cycles] }\end{array}$ \\
\hline Baseline & 6 & 170922 & $4085 \mathrm{I}$ \\
5T & 8 & 224054 & 42377 \\
IOT & 9 & 237903 & 56042 \\
$45 T$ & 3 & 1043743 & 44277 \\
\hline
\end{tabular}

in the road simulator or in the bench test without pause). Kim et al. [29] for example showed that compressive stresses acting in multisite crack fatigue tests alter fatigue life, increasing it. Frequency changes and contact pressure have also been shown to affect fretting fatigue life in titanium alloys [30]. These inertial loads may be larger than the typical spectrum loads, resulting, for example, in an "overload" (which could justify the delay in fatigue propagation). It is difficult, however, to justify why this effect of transient loads would be dependent on the pause duration. 
Another possible origin for this effect would be the action of environmental variables. It is a fact that a sample subjected to periodic pauses will suffer larger environmental attack, compared with a sample subject to a continuous test. Environmental attack, however, usually works in the opposite way, reducing fatigue life, and not increasing it. This hypothesis, therefore is highly questionable.

In other words, the cause for this phenomenon has yet to be investigated. The present results clearly point out, however, that the phenomenon exists, and that it can justify the differences in durability observed in proving ground tests compared with laboratory tests. The effect, however, must be investigated in a more fundamental fashion (in a laboratory, with standard specimens, to further reduce the influence of uncontrollable variables). Questions which arise from the present work are:

- Is this effect limited to the studied component, or does it apply also to other automobile components?

- Is this effect limited to fatigue in (carbon) steels, or does it apply also to other materials (either metallic or non-metallic)?

- Is this effect characteristic of VA loading (and of this particular spectrum) or does it apply to the CA loading (alternatively, for other spectra)?

Answering these questions requires a full research program, which is outside of the scope of the present work. The authors, however, urge the community to investigate the phenomenon. The answer to these questions is particularly important in the present days, since periodic pauses are used as a means of temperature control in very high cycle fatigue testing [3 I-35]. Stanzl-Tschegg et al. [32] in particular, showed considerably larger fatigue lifes in an Al7SiMg alloy when submitted to an ultrasonic VA fatigue test, compared with the equivalent CA program. In both cases the test is periodically interrupted to allow heat dissipation, but the extent of the pauses are not reported. The present results suggest, that, at least, any pause applied to a fatigue test should be clearly specified.

\section{CONCLUSIONS}

In the present work, fatigue testing of an automobile component (a horn bracket of a passenger's vehicle) has been performed following different schedules. Testing the component mounted in the vehicle, in the spirit of Betriebsfestigkeit leads to diverging results depending on whether the test is conducted in a proving ground, or using a road simulator with equivalent levels of accumulated damage. The difference is expressed in a higher durability of the component when the test is conducted in the field (failure at $18 \%$ of the total test duration) compared with the laboratory result (failure at $11 \%$ of the total test duration). This difference cannot be attributed the loading spectra in both tests, which was shown to be completely equivalent. Then, this difference in durability was linked to the existence of pauses in the field test, which are seldom present in the laboratory test, by using bench tests of the component using the spectrum acquired in the field test and artificially introducing periodic pauses. In this way, the average fatigue life of the component, which corresponds to 170922 cycles in the continuous test, can be raised consistently to 1043743 cycles by using 45 hour periodic pauses each 100000 cycles.

\section{Acknowledgements}

This work has been financially supported by the Brazilian National Research Council (CNPq, Brasília-DF, Brazil) under Proj. 3 12424/2013-2. The support by Volkswagen do Brasil SA, in the form of measurements and samples, is gratefully appreciated.

\section{REFERENCES}

I Schütz W. A history of fatigue. Engineering Fracture Mechanics. 1996;54:263-300.

2 Berger C, Eulitz KG, Heuler P, Kotte KL, Naundorf H, Sonsino CM, et al. Betriebsfestigkeit in Germany - an overview. International Journal of Fatigue. 2002;24:603-625.

3 Schijve J. Fatigue of structures and materials in the 20th century and the state of the art. International Journal of Fatigue. 2003;25:679-702.

4 Socie DF. Fatigue-life prediction using local stress-strain concepts. Experimental Mechanics. 1977; 17:50-56.

5 Skorupa M. Load interaction effects in fatigue crack growth under variable amplitude loading: a literature review part I: empirical trends. Fatigue \& Fracture of Engineering Materials \& Structures. 1998;21:897-1006.

6 Skorupa M. Load interaction effects in fatigue crack growth under variable amplitude loading: a literature review part II: qualitative interpretation. Fatigue \& Fracture of Engineering Materials \& Structures. 1999;22:905-926.

7 Schijve J. Fatigue of structure and materials. Boston: Kluwer Academic; 200 I.

8 Stephens R, Fatemi A. Metal fatigue in engineering, 2nd ed. New York: John Wiley and Sons; 2000. 
9 Suresh S. Fatigue of materials, 2nd ed. New York: Cambridge University Press; 2004.

10 Schön CG. Mecânica dos materiais. Rio de Janeiro: Elsevier; 2013.

I I Probst EP, Hillberry BM. Fatigue crack delay and arrest due to single peak tensile overloads. AIAA Journal. 1974;12:330-335.

12 Fleck NA. Fatigue crack growth due to periodic underloads and overloads. Acta Metallurgica. 1985;33:1339-1354.

13 Pompetzki MA, Topper TH, DuQuesnay DL. The effect of compressive underloads and of tensile overloads on fatigue damage accumulation in $\{$ SAE I045 $\}$ steel. International Journal of Fatigue. 1990; 12:207-2 3.

14 Geary W. A review on some aspects of fatigue crack growth under variable amplitude loading. International Journal of Fatigue. 1992; 14:377-386.

I5 Sadananda K, Vasudevan AK, Holtz RL, Lee EU. Analysis of overload effects and related phenomena. International Journal of Fatigue. 1999;21:S233-S246.

16 Colombo C, Du Y, James MN, Paterson EA, Vergani L. On crack tip shielding due to plasticity-induced closure after an overload. Fatigue \& Fracture of Engineering Materials \& Structures. 2010;33:766-777.

17 Elber W. Fatigue crack closure under cyclic tension. Engineering Fracture Mechanics. 1970;2:37-45.

18 Borrego LP, Antunes FV, Costa JD, Ferreira JM. Numerical simulation of plasticity induced crack closure under overloads and high-low blocks. Engineering Fracture Mechanics. 2012;95:57-7I.

19 Sadananda K, Sarkar S, Kujawski D, Vasudevan AK. A two-parameter analysis of S-N fatigue life using Ds and $s_{\text {max }}$. International Journal of Fatigue. 2009;31:1648-1659.

20 Huang HL, Ho NJ. The observation and analysis of the dislocation morphology of fatigue crack tips at steady state propagation rates subject to a single peak load. Materials Science and Engineering A. 200I;298:25I-26I .

2I Meyer AA, Adams DD. Damage identification of ground vehicle through passive probing of suspension damping. Experimental Mechanics. 2012;53:557-569.

22 Angelo CM, Machado FAC, Schön CG. Influence of tires sizes over automobile body spectrum loads and fatigue damage accumulation. Materials \& Design. 2015;67:385-389.

23 Straub T, Berwind MF, Kennerknecht T, Lapusta Y, Eberl C. Small-scale multiaxial setup for damage detection into the very high cycle fatigue regime. Experimental Mechanics. 2015;55: I285-1299.

24 Associação Brasileira de Normas Técnicas. NBR 5483: Acústica - medição de ruído emitido por buzinas instaladas em veículos automotores - método de engenharia. Rio de Janeiro: ABNT; 2006.

25 HBM do Brasil. Produtos. 2013. Available at http://www.hbm.com/pt/menu/produtos/componentes-de-pesagem/ celulas-de-carga/z6/

26 European Committee for Standardization. EN 10002-I - metallic materials - tensile testing - part I: Method of test at ambient temperature. Brussels: CEN; $200 \mathrm{I}$.

27 American Society for Testing Materials. ASTM E 1049-89 - standard practices for cycle counting in fatigue analysis. West Conshohocken: ASTM; 20I I. http://dx.doi.org/I0.1520/E I049-85RI IEOI.

28 Percival D, Walden A. Spectral analysis in physical application. Cambridge: Cambridge University Press; 1993.

$29 \mathrm{Kim} \mathrm{JH}$, Chau Dinh T, Zi G, Kong JS. The effect of compression stresses, stress level and stress order of fatigue crack growth of multiple site damage. Fatigue \& Fracture of Engineering Materials \& Structures. 2012;33:903-917.

30 lyer K, Mall S. Effects of cyclic frequencies and contact pressure in fretting fatigue under two-level block loading. Fatigue \& Fracture of Engineering Materials \& Structures. 2000;23:335-346.

3I Stanzl-Tschegg SE. Fracture mechanisms and fracture mechanics at ultrassonic frequencies. Fatigue \& Fracture of Engineering Materials \& Structures. 1999;22:567-579.

32 Stanzl-Tschegg SE, Mayer H, Stich A. Variable amplitude loading in the very high-cycle fatigue regime. Fatigue \& Fracture of Engineering Materials \& Structures. 2002;25:887-896.

$33 \mathrm{Mayer} \mathrm{H}$. Ultrasonic torsion and tension - compression fatigue testing: measuring principles and investigations in 2024-T35 I aluminum alloy. International Journal of Fatigue. 2006;28: I 446- I 455.

34 Backe D, Balle F, Eifler D. Fatigue testing of CFRP in the very high cycle fatigue (VHCF) regime at ultrasonic frequencies. Composites Science and Technology. 2015; 106:93-99.

35 Mayer $\mathrm{H}$. Recent developments in ultrasonic fatigue. Fatigue \& Fracture of Engineering Materials \& Structures. 2016;39:3-29.

Received: 17 Jul. 2017

Accepted: 28 Ago. 2018 